\title{
Tyrosine Kinase Inhibitor versus Physician Choice Chemotherapy in Second-Line Epidermal Growth Factor Receptor Mutation Non-Small Cell Lung Cancer: Post hoc Analysis of Randomized Control Trial
}

\begin{abstract}
Background: There is a paucity of prospective data for patients who progressed after first-line tyrosine kinase inhibitor (TKI) or pemetrexed doublet among epidermal growth factor receptor (EGFR) mutation-positive metastatic non-small cell lung cancer (NSCLC). Aim: The aim of the study was to evaluate the outcome of second-line therapy in patients who progressed on TKI or pemetrexed doublet in EGFR mutation-positive NSCLC. Objective: The objective of the study was to calculate response rates, progression-free survival (PFS), and overall survival (OS) of patients receiving second-line therapy in EGFR mutation NSCLC. Materials and Methods: Post hoc analysis of second-line therapy among patients enrolled in randomized control trial comparing TKI versus pemetrexed doublet in EGFR mutation NSCLC. Kaplan-Meir statistics were used for PFS and OS. Impact of variables was measured with Log-rank test. Results: One hundred and eighty-seven patients who progressed on first-line therapy and received second-line agents were analyzed. Male:female: 110 (56.3\%):77 (41.2\%). One hundred and thirteen patients received gefitinib, while 74 received chemotherapy. Response rate (complete response + partial response) was $53 \%$ versus $24 \%$ in gefitinib versus chemotherapy group (RECIST v1.1). PFS was 7.4 months versus 4.4 months $(P=0.001)$, while OS was 14 months versus 9.7 months $(P=0.007)$, in gefitinib versus chemotherapy group, respectively. Response to TKI significantly improves PFS (10.8 months vs. 3.9 months, $P=0.001)$ and OS (21.4 months vs. 8.9 months, $P=0.03)$. Rash, pruritus, dry skin, fatigue, diarrhea, and paronychia were common toxicities of TKI. Conclusion: Second-line TKI improves outcome in EGFR mutation-positive NSCLC who progressed after first-line chemotherapy. Response to therapy, whether with TKI or chemotherapy, favorably impacts outcomes.
\end{abstract}

Keywords: Gefitinib, pemetrexed, second-line lung cancer

\section{Introduction}

Platinum doublet chemotherapy has been the historical backbone of therapy for advanced metastatic non-small cell lung cancer (NSCLC). ${ }^{[1]}$ Pemetrexed platinum doublet is accepted standard of care for chemotherapy-naive nonsquamous NSCLC. ${ }^{[2]}$ However, recently, use of tyrosine kinase inhibitors (TKIs) in epidermal growth factor receptor (EGFR) mutation-positive metastatic NSCLC has shown to significantly improve progression-free survival (PFS) when used upfront compared to chemotherapy. ${ }^{[3-11]}$ However, caveat to these studies is that, except for LUX-Lung 3, all have nonpemetrexed doublet in comparator arm and have few patients from Indian Subcontinent. ${ }^{[12,13]}$ Moreover, none had maintenance pemetrexed in control

\footnotetext{
This is an open access journal, and articles are distributed under the terms of the Creative Commons Attribution-NonCommercial-ShareAlike 4.0 License, which allows others to remix, tweak, and build upon the work non-commercially, as long as appropriate credit is given and the new creations are licensed under the identical terms.
}

For reprints contact: reprints@medknow.com arm, which is now an accepted standard worldwide. We had earlier reported outcomes of Phase III randomized trial comparing first-line TKI and pemetrexed doublet in EGFR mutation-positive NSCLC. ${ }^{[14]}$ We further report post hoc analysis of outcomes and toxicities of patients who progressed after first-line therapy including maintenance pemetrexed and managed to receive second-line chemotherapy or TKIs in EGFR mutation positive NSCLC.

\section{Materials and Methods}

Our group from tertiary cancer center at Mumbai, India, has initially reported outcomes of Phase III, double-arm, single-center, open-label randomized control trial comparing gefitinib versus pemetrexed platinum doublet in first-line

How to cite this article: Noronha V, Pandey A,
Patil V, Joshi A, Choughule AB, Bhattacharjee A, et al.
Tyrosine kinase inhibitor versus physician choice
chemotherapy in second-line epidermal growth factor
receptor mutation non-small cell lung cancer: Post hoc
analysis of randomized control trial. Indian J Med
Paediatr Oncol 2018;39:493-8.

How to cite this article: Noronha $\mathrm{V}$, Pandey $\mathrm{A}$, Patil V, Joshi A, Choughule AB, Bhattacharjee A, et al. Tyrosine kinase inhibitor versus physician choice chemotherapy in second-line epidermal growth factor analysis of randomized control trial. Indian $\mathrm{J}$ Med Paediatr Oncol 2018;39:493-8.

\author{
Vanita Noronha, \\ Avinash Pandey ${ }^{1}$, \\ Vijay Patil, \\ Amit Joshi, \\ Anuradha Bharat \\ Choughule $^{2}$, \\ Atanu \\ Bhattacharjee $^{3}$, \\ Rajiv Kumar ${ }^{4}$, \\ Supriya Goud, \\ Sucheta More, \\ Anant Ramaswamy, \\ Ashay Karpe, \\ Nikhil Pande, \\ Arun \\ Chandrasekharan, \\ Alok Goel, \\ Vikas Talreja, \\ Abhishek Mahajan ${ }^{5}$, \\ Amit Janu, \\ Nilendu Purandare ${ }^{6}$, \\ Kumar Prabhash
}

Departments of Medical Oncology, ${ }^{2}$ Molecular Genetics, ${ }^{4}$ Pathology,

${ }^{5}$ Radio Diagnosis and ${ }^{6}$ Nuclear

Medicine, Tata Memorial Hospital, ${ }^{3}$ Department of Biostatistics, ACTREC, Tata Memorial Centre, Mumbai, Maharashtra, ${ }^{1}$ Department of Medical Oncology, Indira Gandhi Institute of Medical Sciences, Patna, Bihar, India

Address for correspondence: Dr. Kumar Prabhash,

Department of Medical Oncology, Tata Memorial

Hospital, Mumbai,

Maharashtra, India.

E-mail:kprabhash1@gmail.com

Access this article online

Website: www.ijmpo.org

DOI: 10.4103/ijmpo.ijmpo_219_17 Quick Response Code:

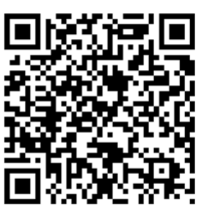


EGFR mutation-positive nonsquamous advanced metastatic NSCLC. Out of 290 patients enrolled, 257 progressed after first-line therapy. One hundred and eighty-seven out of these 257 went on to receive second-line physician choice agents; remaining others were not eligible due to various reasons such as poor performance status, progressive brain metastasis, asymptomatic progression, patient not willing for further therapy, and clinician decision [CONSORT diagram Figure 1]. This study was approved by the Institutional Ethics Committee of our Institute.

Demographic and clinical profile of patients who went on to receive physician choice second-line therapy was recorded including age, sex, performance status before initiation of second-line therapy, smoking status, EGFR mutation, and tobacco chewing. For EGFR mutation analysis, DNA was extracted from formalin fixed, paraffin-embedded tumor block and amplified for exon 18, 19, and 21 using nested PCR which has been standardized and validated at our institute molecular laboratory. ${ }^{[15,16]}$

As per physician choice, any of the following schedules of drug administration was followed:

a. Gefitinib $250 \mathrm{mg}$ daily per oral until progressive disease, intolerable toxicity, or other approved criteria for discontinuation

b. Pemetrexed $500 \mathrm{mg} / \mathrm{m}^{2}$ intravenous over $10 \mathrm{~min}$ with or without carboplatin (area under the curve [AUC] $=5$ ) over $60 \mathrm{~min}$ intravenous infusion, with appropriate antiemetic prophylaxis along with B12 (1000 mcg intramuscularly 1 week before chemotherapy and repeated every 12 weeks) and folic acid (5 $\mathrm{mg}$ once a day daily) continued till 3 weeks after last dose of pemetrexed

c. Weekly paclitaxel at $100 \mathrm{mg} / \mathrm{m}^{2}$ infused over $60 \mathrm{~min}$, continued till progressive disease, Grade II neuropathy or other intolerable toxicity

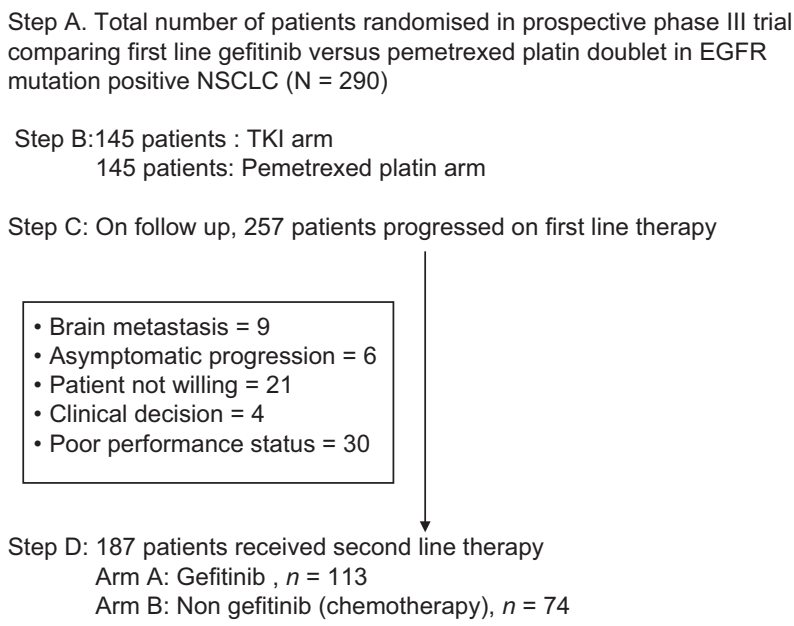

Figure 1: CONSORT diagram: Schematic representation of patients on prospective randomised trial who received second line therapy after progression to first line d. Gemcitabine $1000 \mathrm{mg} / \mathrm{m}^{2}$ infused over $20 \mathrm{~min}$ D1 and D8, with or without cisplatin $75 \mathrm{mg} / \mathrm{m}^{2}$ over $60 \mathrm{~min}$ with adequate intravenous hydration or carboplatin $(\mathrm{AUC}=5)$ over $60 \mathrm{~min}$ intravenous infusion

Response evaluation was done at every 12 weeks with contrast-enhanced computerized tomography of chest and associated metastatic sites in patient receiving second-line therapy including gefitinib and chemotherapy, recorded and compared as per RECIST criteria version 1.1. Toxicity with the use of second-line agents was prospectively recorded at every cycle visit of chemotherapy and every 2 weeks for the first 2 months for TKIs and thereafter monthly. Patients were followed through clinical charts in each outpatient department visit during and after completion of therapy including telephonic calls.

PFS was defined as time interval from the start of second-line agent to objective progressive disease and change in treatment or death from any cause. Overall survival (OS) was defined as time interval from start of second-line agent till death from any cause. PFS and OS were calculated as per Kaplan-Meir statistics. Log-rank test was used to compare the impact of several prognostic factors such as age, sex, smoking, tobacco use, EGFR mutation, performance status, response rates, on PFS and OS.

\section{Results}

Patients were enrolled in prospective randomized Phase III trial from February 2012 to April 2016, all having EGFR classical mutation and metastatic advanced nonsquamous NSCLC. One hundred and eighty-seven out of 257 (73\%) patients, who progressed after first-line therapy, went on to receive physician choice second-line therapy. Gefitinib was the most common agent used $(n=113)$ followed by pemetrexed platinum doublet $(n=58)$, weekly paclitaxel $(n=6)$, pemetrexed alone $(n=1)$, and other agents $(n=9)$. Male patients and smokers were 110 and 39 , respectively. One hundred and forty-three (76\%) patients had a good performance status (PS 0-1), whereas $14(7.5 \%)$ had PS 3 before starting second-line agents. Eighty-eight out of one hundred and eighty-seven (47\%) patients underwent re-biopsy after progression on first-line agents. Most common site of biopsy was lung $(n=79)$, followed by extrathoracic site $(n=6)$ and lymph node $(n=3)$.

Of all patients re-biopsied, three patients had nonadenocarcinoma histology, with squamous cell, small cell, and poorly differentiated carcinoma each, while remaining 77 had similar adenocarcinoma histology, and in 8 patients, sample was not representative [Table 1]. Gefitinib was used in $36 / 64,76 / 116$, and $1 / 4$ patients with exon 21 , exon 19 , and exon 18 mutation, respectively, while remaining patients received nongefitinib chemotherapeutic agents.

Median follow-up of patients is 14 months. Patients receiving gefitinib had better response rates' complete 


\begin{tabular}{|c|c|c|}
\hline \multicolumn{3}{|c|}{$\begin{array}{l}\text { Table 1: Demographic, clinical, and treatment profile } \\
\text { of patients on second-line therapy in nonsquamous } \\
\text { mutation-positive nonsmall cell lung cancer }\end{array}$} \\
\hline Profile $(n=187)$ & Characteristics & Remarks (\%) \\
\hline Age & Median 54 years & Range $27-76$ year \\
\hline \multicolumn{3}{|l|}{ Sex } \\
\hline Male & 110 & 59 \\
\hline Female & 77 & 41 \\
\hline \multicolumn{3}{|l|}{ Smoking } \\
\hline Yes & 39 & 21 \\
\hline No & 148 & 79 \\
\hline \multicolumn{3}{|l|}{ Tobacco chewing } \\
\hline Yes & 75 & 40 \\
\hline No & 112 & 60 \\
\hline \multicolumn{3}{|l|}{ EGFR mutation } \\
\hline Exon 21 & 64 & 34 \\
\hline Exon 19 & 119 & 64 \\
\hline Exon 18 & 4 & 2 \\
\hline \multicolumn{3}{|l|}{ PS } \\
\hline PS 0-1 & 143 & 76 \\
\hline PS 2 & 30 & 16 \\
\hline PS 3 & 14 & 7.5 \\
\hline \multicolumn{3}{|l|}{ Second line agents } \\
\hline Gefitinib & 113 & 60 \\
\hline Others (nongefitinib) & 74 & 40 \\
\hline Pemetrexed platinum & 58 & 31 \\
\hline Other chemotherapy & 16 & 9 \\
\hline Response rates & Gefitinib & Nongefitinib \\
\hline $\mathrm{SD}+\mathrm{PD}$ & 53 & 56 \\
\hline $\mathrm{CR}+\mathrm{PR}$ & 60 & 18 \\
\hline
\end{tabular}

SD - Stable disease; PD - Progressive disease; PR - Partial response; CR - Complete response; PS - Performance status

response partial response $(\mathrm{CR}+\mathrm{PR})$ compared with nongefitinib group, 60/113 (53\%) versus 18/74 (24\%) when used in second line in EGFR mutation positive, metastatic NSCLC. Among nongefitinib group $(n=74)$, pemetrexed platinum doublet had better response rate $(\mathrm{CR}+\mathrm{PR})$, $16 / 58(28 \%)$ compared to other agents 2/16 (12\%). Median PFS and OS of entire cohort of patients are 5.9 months and 13 months, respectively. Gefitinib group had significantly better PFS (7.4 months vs. 4.4 months, $P=0.001)$ and OS (14 months vs. 9.7 months, $P=0.03$ ) compared to nongefitinib group.

Response to therapy (CR $+\mathrm{PR})$ was significantly associated with improved PFS (10.8 vs. 3.9 months, $P=0.001)$ in gefitinib as well as in nongefitinib group (6.2 months vs. 3.8 months, $P=0.007)$. Similarly, OS was significantly improved in both gefitinib (21.4 months vs. 8.9 months, $P=0.01)$ and nongefitinib group (11.7 months vs. 8.8 months, $P=0.03$ ) for patients with good response to therapy. None of the other prognostic factors such as age, sex, performance status, EGFR mutation status, smoking, and tobacco use had a significant impact on outcome, except gefitinib group had better survival among nonsmokers [Table 2].
Patients receiving gefitinib had diverse but mostly low-grade toxicity compared to nongefitinib group such as diarrhea, rash, paronychia, pruritus, anorexia, fatigue, and dry skin [Table 3]. Among chemotherapy group, neutropenia was the most common toxicity including life-threating febrile neutropenia (5.5\%). After progression from second-line therapy, $87 / 187 \quad(46 \%)$ went on to receive third-line agents. Weekly paclitaxel $\left(100 \mathrm{mg} / \mathrm{m}^{2}\right)$ was the most common regimen $(43 / 87,49 \%)$ followed by docetaxel (15/87) and gefitinib (10/87).

\section{Discussion}

First-line pemetrexed platinum doublet and TKIs are both approved as a standard of care in metastatic nonsquamous NSCLC. ${ }^{[2,3]}$ However, upfront TKI has shown significant benefit in improving PFS when used upfront compared to chemotherapy in EGFR mutation-positive NSCLC. ${ }^{[3-11]}$ Despite the use of TKIs or pemetrexed doublet, almost all patients subsequently suffer disease progression and become eligible to receive second-line therapy with respect to age, performance status, and comorbidities. TKIs are a valid second-line option for patients who progressed on first-line chemotherapy and harbor EGFR classical mutation. Similarly, patients who progressed on first-line TKI, merit systemic chemotherapy where pemetrexed is more rational choice compared to docetaxel in nonsquamous NSCLC, having similar outcomes with reduced toxicities. ${ }^{[17]}$ We report outcomes and toxicities of physician choice second-line agents who progressed after first-line TKIs or pemetrexed platinum doublet with or without maintenance pemetrexed in patients with EGFR mutation-positive advanced metastatic nonsquamous NSLC exclusively from the Indian subcontinent.

In the initial studies, gefitinib in unselected patients produces response rate of $15 \%-20 \%$ after progression on 1-2 lines of platinum-based chemotherapy. ${ }^{[18,19]}$ Gefitinib when compared with docetaxel as second-line therapy in randomized Phase II/III trial did not show any improvement in PFS and OS in unselected patients. ${ }^{[20-23]}$ However, post hoc subset analysis showed better response rate (42\% vs. $21 \%)$ and PFS with gefitinib in EGFR mutation-positive subset of NSCLC. ${ }^{[24]}$ Similarly, our study demonstrated superior response rates in selected EGFR classical mutation NSCLC with gefitinib compared to chemotherapy (53\% vs. $24 \%, P=0.03)$ which translated into improved PFS (7.4 months vs. 4.4 months, $P=0.001$ ) and OS (14 months vs. 9.7 months, $P=0.03$ ) as second-line therapy.

Several randomized Phase III trial has now compared gefitinib with nonpemetrexed doublet in first line and shown better response rates $(60 \%-84 \%$ vs. $30 \%-47 \%)$ and PFS. ${ }^{[7-11]}$ LUX-Lung 3 is the only randomized Phase III trial which has compared TKI (afatinib) with the standard of care pemetrexed platinum doublet, without maintenance, and shown significantly improved PFS 
Table 2. Impact of prognostic factors in gefitinib and nongefitinib group on median progression-free survival and median overall survival - log rank test (pair-wise over each stratum)

\begin{tabular}{|c|c|c|c|c|c|c|c|}
\hline \multirow[t]{2}{*}{ Factors } & \multirow[t]{2}{*}{ Group } & \multicolumn{3}{|c|}{ PFS (months) } & \multicolumn{3}{|c|}{ OS (months) } \\
\hline & & Gefitinib & Nongefitinib & $P$ & Gefitinb & Nongefitinib & $P$ \\
\hline \multirow[t]{2}{*}{ Age (years) } & $\leq 54$ & 7.4 & 4.7 & NS/NS & 15.2 & 10.7 & NS/NS \\
\hline & $>54$ & 8.3 & 4.9 & & 13.4 & 7.4 & \\
\hline \multirow[t]{2}{*}{ Sex } & Male & 6.5 & 4.1 & NS/NS & 13.7 & 8.86 & NS/NS \\
\hline & Female & 8.7 & 4.5 & & 15.2 & 11.5 & \\
\hline \multirow[t]{2}{*}{ Smoking } & Yes & 6.2 & 3.6 & NS/NS & $11.1^{\#}$ & 9.7 & $0.03 / \mathrm{NS}$ \\
\hline & No & 8.0 & 4.4 & & $15.2^{\#}$ & 9.7 & \\
\hline \multirow[t]{2}{*}{ Tobacco } & Yes & 6.5 & 4.5 & NS/NS & 13.8 & 11.2 & NS/NS \\
\hline & No & 7.6 & 4.4 & & 15.2 & 9.5 & \\
\hline \multirow[t]{3}{*}{ EGFR mut } & Exon 21 & 5.7 & 4.1 & $\mathrm{NS} / \mathrm{NS} / \mathrm{NS}$ & 11.5 & 8.2 & $\mathrm{NS} / \mathrm{NS} / \mathrm{NS}$ \\
\hline & Exon 19 & 8.0 & 4.5 & & 14.8 & 9.7 & \\
\hline & Exon 18 & 8.4 & 2.3 & & 14.0 & 9.1 & \\
\hline \multirow[t]{2}{*}{ PS } & $0-1$ & 7.5 & 5.2 & NS/NS & 15.7 & 11.3 & NS/NS \\
\hline & $2-3$ & 6.1 & 4.3 & & 11.5 & 7.2 & \\
\hline \multirow[t]{2}{*}{ Response } & $\mathrm{SD}+\mathrm{PD}$ & 3.9 & 3.8 & $0.00 / 0.07^{s}$ & 8.9 & 8.8 & $0.00 / 0.03^{s}$ \\
\hline & $\mathrm{CR}+\mathrm{PR}$ & 10.8 & 6.2 & & 21.4 & 11.7 & \\
\hline
\end{tabular}

\# OS is significantly better in nonsmokers compared to smokers in gefitinib group, $P=0.03$, ${ }^{\$} \mathrm{CR}+\mathrm{PR}$ responses had significantly better PFS and OS in both gefitinb and nongefitinib group. PS - Performance status, EGFR mut - Epidermal Growth Factor receptor mutation type; SD - Stable disease; PD - Progressive disease; PR - Partial response; CR - Complete response; NS - Not significant, OS - Overall survival

Table 3. Toxicity recorded among patients receiving gefitinib versus nongefitinib therapy, as per Common toxicity criteria v4.03

\begin{tabular}{|c|c|c|c|c|c|c|c|c|}
\hline \multirow[t]{2}{*}{ Toxicity } & \multicolumn{4}{|c|}{ Gefitinib group $(n=113)$} & \multicolumn{4}{|c|}{ Nongefitinib group $(n=74)$} \\
\hline & Group 1 & Group 2 & Group 3 & Group 4 & Group 1 & Group 2 & Group 3 & Group 4 \\
\hline Anaemia & 43 & 12 & 5 & 0 & 28 & 15 & 3 & 0 \\
\hline Thrombocytopena & 7 & 4 & 1 & 1 & 8 & 3 & 2 & 1 \\
\hline Neutropenia & 1 & 4 & 0 & 0 & 10 & 2 & 2 & 4 \\
\hline SGOT increased & 31 & 4 & 2 & 0 & 14 & 2 & 0 & 0 \\
\hline SGPT increased & 31 & 5 & 5 & 0 & 18 & 4 & 0 & 0 \\
\hline Hypoalbuminemia & 14 & 12 & 2 & 0 & 15 & 6 & 0 & 0 \\
\hline Diarrhea & 14 & 7 & 3 & 0 & 7 & 6 & 6 & 0 \\
\hline Skin rash & 34 & 22 & 8 & 0 & 20 & 4 & 2 & 0 \\
\hline Paronychia & 3 & 2 & 1 & 0 & 1 & 1 & 0 & 0 \\
\hline Mucositis & 8 & 1 & 0 & 0 & 11 & 0 & 2 & 0 \\
\hline Anorexia & 39 & 4 & 1 & 0 & 21 & 4 & 0 & 0 \\
\hline Pruritus & 33 & 2 & 0 & 0 & 16 & 4 & 0 & 0 \\
\hline Nausea & 8 & 2 & 0 & 0 & 9 & 2 & 0 & 0 \\
\hline Vomiting & 8 & 3 & 1 & 0 & 4 & 0 & 2 & 0 \\
\hline Fatigue & 45 & 10 & 2 & 0 & 24 & 15 & 3 & 0 \\
\hline Constipation & 9 & 0 & 1 & 0 & 11 & 2 & 0 & 0 \\
\hline Bilirubin increase & 5 & 1 & 0 & 0 & 6 & 0 & 0 & 0 \\
\hline Creatinine increase & 6 & 3 & 0 & 0 & 6 & 3 & 0 & 0 \\
\hline Hypokalemia & 6 & 1 & 2 & 0 & 6 & 2 & 0 & 0 \\
\hline Pneumonitis & 1 & 2 & 0 & 0 & 1 & 1 & 0 & 1 \\
\hline Dry skin & 38 & 11 & 1 & 0 & 13 & 3 & 1 & 0 \\
\hline
\end{tabular}

SGPT - Serum glutamate pyruvate transaminase; SGOT - Serum glutamate-oxaloacetate transaminase

of 11.6 months versus 6.9 months. ${ }^{[12]}$ Our study, with second-line gefitinib, consolidates the evidence that TKIs after progression from first-line chemotherapy retains its drug sensitivity and provides a better outcome in EGFR mutation-positive NSCLC compared to any other second-line chemotherapy.
Hanna et al. reported largest randomized trial of pemetrexed versus docetaxel in second-line NSCLC, where pemetrexed has shown modest response rates of $9 \%$ with PFS of 2.9 months and OS of 8.3 months which was clinically equivalent to docetaxel albeit with reduced toxicities. ${ }^{[17]}$ Our study produced much better 
response rates (28\%) with PFS and OS of 4.4 months and 9.7 months, respectively, with pemetrexed platinum doublet second-line therapy. This discordant outcome can be explained by the fact that all patients in our study receiving pemetrexed platinum doublet in second line were platinum naive and have not been exposed to any chemotherapeutic agent before. Moreover, as against Hanna et al., majority of our patients have received pemetrexed platinum doublet $(58 / 74)$ compared to pemetrexed alone, being platinum naive.

Majority of our patients who received second-line pemetrexed doublet had prior received gefitinib in first line as per the provision of Phase III randomized trial and had shown better response rate and PFS in first line. ${ }^{[14]}$ Similar to Hanna et al., where better response to second-line chemotherapy, was demonstrated in the same cohort of patients who had complete or PR to first-line agents, in our study better response to second-line pemetrexed doublet could also be attributed to higher response produced by first-line gefitinib (65\% vs. 43\%) in EGFR mutation-positive NSCLC. ${ }^{[14,17]}$ This further contributes to the fact that response to first-line agents is strong prognostic and predictive factor of outcome with second-line agents. Pemetrexed doublet in our study produced $<5 \%$ incidence of Grade $3 / 4$ anemia and thrombocytopenia, while febrile neutropenia was $1.3 \%$. This is comparable to toxicity reported in cisplatin-pemetrexed arm of LUX-Lung 3 trial and marginally more than Hanna et al., where single agent pemetrexed was used..$^{[12,17]}$

Rash, diarrhea, fatigue, pruritus, and paronychia are the most common toxicities seen with gefitinib while nongefitinib chemotherapy had higher hematological toxicities. In nongefitinib group, while 78\% had received pemetrexed platinum doublet, remaining patients received weekly paclitaxel, pemetrexed, docetaxel, and gemcitabine, thus making the overall comparator (nongefitinib group) heterogeneous when compared to second-line gefitinib. As physician choice was exercised to select patients and chemotherapeutic agents, selection bias cannot be ruled out with PS 2-3 patients receiving single-agent chemotherapy compared to pemetrexed doublet otherwise. After progression from second-line agents, $46 \%$ patients also received third-line agents, mainly weekly paclitaxel. Hence, impact of third line chemotherapy on OS cannot be completely nullified.

\section{Conclusion}

Among exclusive EGFR mutation-positive NSCLC, our study is the first to report outcomes of gefitinib versus physician choice chemotherapy as second line among patients from Indian subcontinent. Favorable response rate after second-line agents is one of the strongest prognostic factors for overall outcome. TKIs after progression on first-line chemotherapy improves response rates, PFS, and OS compared to chemotherapy in EGFR mutation-positive NSCLC.

\section{Financial support and sponsorship}

Nil.

\section{Conflicts of interest}

There are no conflicts of interest.

\section{References}

1. D'Addario G, Pintilie M, Leighl NB, Feld R, Cerny T, Shepherd FA, et al. Platinum-based versus non-platinum-based chemotherapy in advanced non-small-cell lung cancer: A meta-analysis of the published literature. J Clin Oncol 2005;23:2926-36.

2. Scagliotti GV, Parikh P, von Pawel J, Biesma B, Vansteenkiste J, Manegold C, et al. Phase III study comparing cisplatin plus gemcitabine with cisplatin plus pemetrexed in chemotherapy-naive patients with advanced-stage non-small-cell lung cancer. J Clin Oncol 2008;26:3543-51.

3. Lee CK, Brown C, Gralla RJ, Hirsh V, Thongprasert S, Tsai CM, et al. Impact of EGFR inhibitor in non-small cell lung cancer on progression-free and overall survival: A meta-analysis. J Natl Cancer Inst 2013;105:595-605.

4. Zhou $\mathrm{C}, \mathrm{Wu}$ YL, Chen G, Feng J, Liu XQ, Wang C, et al. Final overall survival results from a randomised, phase III study of erlotinib versus chemotherapy as first-line treatment of EGFR mutation-positive advanced non-small-cell lung cancer (OPTIMAL, CTONG-0802). Ann Oncol 2015;26:1877-83.

5. Rosell R, Carcereny E, Gervais R, Vergnenegre A, Massuti B, Felip E, et al. Erlotinib versus standard chemotherapy as first-line treatment for European patients with advanced EGFR mutation-positive non-small-cell lung cancer (EURTAC): A multicentre, open-label, randomised phase 3 trial. Lancet Oncol 2012;13:239-46.

6. Wu YL, Zhou C, Liam CK, Wu G, Liu X, Zhong Z, et al. First-line erlotinib versus gemcitabine/cisplatin in patients with advanced EGFR mutation-positive non-small-cell lung cancer: Analyses from the phase III, randomized, open-label, ENSURE study. Ann Oncol 2015;26:1883-9.

7. Mok TS, Wu YL, Thongprasert S, Yang $\mathrm{CH}$, Chu DT, Saijo N, et al. Gefitinib or carboplatin-paclitaxel in pulmonary adenocarcinoma. N Engl J Med 2009;361:947-57.

8. Fukuoka $\mathrm{M}$, Wu YL, Thongprasert $\mathrm{S}$, Sunpaweravong $\mathrm{P}$, Leong SS, Sriuranpong V, et al. Biomarker analyses and final overall survival results from a phase III, randomized, open-label, first-line study of gefitinib versus carboplatin/paclitaxel in clinically selected patients with advanced non-small-cell lung cancer in Asia (IPASS). J Clin Oncol 2011;29:2866-74.

9. Mitsudomi T, Morita S, Yatabe Y, Negoro S, Okamoto I, Tsurutani $\mathrm{J}$, et al. Gefitinib versus cisplatin plus docetaxel in patients with non-small-cell lung cancer harbouring mutations of the epidermal growth factor receptor (WJTOG3405): An open label, randomised phase 3 trial. Lancet Oncol 2010;11:121-8.

10. Inoue A, Kobayashi K, Maemondo M, Sugawara S, Oizumi S, Isobe $\mathrm{H}$, et al. Updated overall survival results from a randomized phase III trial comparing gefitinib with carboplatin-paclitaxel for chemo-naïve non-small cell lung cancer with sensitive EGFR gene mutations (NEJ002). Ann Oncol 2013;24:54-9.

11. Maemondo M, Inoue A, Kobayashi K, Sugawara S, Oizumi S, Isobe $\mathrm{H}$, et al. Gefitinib or chemotherapy for non-small-cell lung cancer with mutated EGFR. N Engl J Med 2010;362:2380-8.

12. Sequist LV, Yang JC, Yamamoto N, O’Byrne K, Hirsh V, Mok T, et al. Phase III study of afatinib or cisplatin plus pemetrexed 
in patients with metastatic lung adenocarcinoma with EGFR mutations. J Clin Oncol 2013;31:3327-34.

13. Yang JC, Hirsh V, Schuler M, Yamamoto N, O'Byrne KJ, Mok TS, et al. Symptom control and quality of life in LUX-lung 3: A phase III study of afatinib or cisplatin/pemetrexed in patients with advanced lung adenocarcinoma with EGFR mutations. J Clin Oncol 2013;31:3342-50.

14. Patil VM, Noronha V, Joshi A, Choughule AB, Bhattacharjee A, Kumar R, et al. Phase III study of gefitinib or pemetrexed with carboplatin in EGFR-mutated advanced lung adenocarcinoma. ESMO Open 2017;2:e00168.

15. Chougule A, Prabhash K, Noronha V, Joshi A, Thavamani A, Chandrani P, et al. Frequency of EGFR mutations in 907 lung adenocarcioma patients of Indian ethnicity. PLoS One 2013;8:e76164.

16. Noronha V, Prabhash K, Thavamani A, Chougule A, Purandare N, Joshi A, et al. EGFR mutations in Indian lung cancer patients: Clinical correlation and outcome to EGFR targeted therapy. PLoS One 2013;8:e61561.

17. Hanna N, Shepherd FA, Fossella FV, Pereira JR, De Marinis F, von Pawel J, et al. Randomized phase III trial of pemetrexed versus docetaxel in patients with non-small-cell lung cancer previously treated with chemotherapy. J Clin Oncol 2004;22:1589-97.

18. Fukuoka M, Yano S, Giaccone G, Tamura T, Nakagawa K, Douillard JY, et al. Multi-institutional randomized phase II trial of gefitinib for previously treated patients with advanced non-small-cell lung cancer (The IDEAL 1 trial) [corrected]. J Clin Oncol 2003;21:2237-46.
19. Kris MG, Natale RB, Herbst RS, Lynch TJ Jr., Prager D, Belani CP, et al. Efficacy of gefitinib, an inhibitor of the epidermal growth factor receptor tyrosine kinase, in symptomatic patients with non-small cell lung cancer: A randomized trial. JAMA 2003;290:2149-58.

20. Cufer T, Vrdoljak E, Gaafar R, Erensoy I, Pemberton K; SIGN Study Group. Phase II, open-label, randomized study (SIGN) of single-agent gefitinib (IRESSA) or docetaxel as second-line therapy in patients with advanced (stage IIIb or IV) non-small-cell lung cancer. Anticancer Drugs 2006;17:401-9.

21. Kim ES, Hirsh V, Mok T, Socinski MA, Gervais R, Wu YL, et al. Gefitinib versus docetaxel in previously treated non-small-cell lung cancer (INTEREST): A randomised phase III trial. Lancet 2008;372:1809-18.

22. Maruyama R, Nishiwaki Y, Tamura T, Yamamoto N, Tsuboi M, Nakagawa $\mathrm{K}$, et al. Phase III study, V-15-32, of gefitinib versus docetaxel in previously treated Japanese patients with non-small-cell lung cancer. J Clin Oncol 2008;26:4244-52.

23. Lee DH, Park K, Kim JH, Lee JS, Shin SW, Kang JH, et al. Randomized phase III trial of gefitinib versus docetaxel in non-small cell lung cancer patients who have previously received platinum-based chemotherapy. Clin Cancer Res 2010;16:1307-14.

24. Douillard JY, Shepherd FA, Hirsh V, Mok T, Socinski MA, Gervais R, et al. Molecular predictors of outcome with gefitinib and docetaxel in previously treated non-small-cell lung cancer: Data from the randomized phase III INTEREST trial. J Clin Oncol 2010;28:744-52. 